\title{
Temperature Performance Evaluation of Parabolic Dishes Covered with Different Materials in Iwo, Nigeria
}

\author{
${ }^{* 1}$ F. O. Aweda, ${ }^{1}$ J. A. Akinpelu 2 O. A. Falaiye, ${ }^{1}$ J. 0. Adegboye \\ "Department of Physics and Solar Energy, Bowen University, Iwo, Osun State, Nigeria. \\ ${ }^{2}$ Department of Physics, University of Ilorin, llorin, Nigeria. \\ [Corresponding author: e-mail: francisaweda@gmail.com; aweda.francis@bowenuniversity.edu.ng]
}

ABSTRACT: Solar radiation reaching the earth is considered to be affected by some parameters like diffusion. This radiation is reflected or scattered by air molecules, cloud and aerosols (dust). Parabolic dishes made of different materials (glass, foil and painted surface) were used to concentrate energy on a copper calorimeter filled with water. A thermometer was inserted in each of the copper calorimeter placed at the focus of the dishes. The experiment was performed from March to April (a period of five weeks), from 9:00am to 5:00pm daily with readings obtained at intervals of 30 minutes every day for one week and was later changed to hourly readings for the remaining four weeks. The initial and final temperatures of the water were determined. The parabolic dish with glass material gave the highest temperature of $\mathbf{5 6}^{6} \mathbf{9}^{\mathbf{0}} \mathbf{C}$ followed by foil with an average temperature of $48.7^{\circ} \mathrm{C}$ and painted silver colour with an average temperature of $45.1^{0} \mathrm{C}$ for the daily variation. For the other weeks, the average temperature of the dish with glass was $56.7^{0} \mathrm{C}$ for foil, $46.9^{\circ} \mathrm{C}$ and painted silver colour, $40.8^{0} \mathrm{C}$. The parabolic dish with glass is able to generate a higher temperature compared with foil and painted silver colour.

Keywords: Glass, Foil, Silver Colour and Parabolic Dish.

\section{INTRODUCTION}

Parabolic dish is a good collector of solar radiation reaching the earth. The temperature performance evaluation of parabolic dishes covered with different material (solar collector) gives more explanation of solar rays reaching the earth Manav et al., (2015). According to Manav et al. (2015), the sun is the only star of our solar system located at its center. The sun is a sphere of intensely hot gaseous matter with a diameter of $1.39 \times 10^{9} \mathrm{~m}$ and is about $1.5 \times 10^{11} \mathrm{~m}$ away from the earth. The sun rotates on its axis once about every four weeks Manav et al., (2015). The intensity of solar radiation per unit time on a unit surface outside the earth's atmosphere is known as "solar constant" Manav et al., (2015).

Muhammad-Sukki et al., (2012), reported that solar energy can be converted into thermal energy either by flat plate collector or a concentrator. Different types of concentrators include parabolic trough collector, parabolic dish and linear Fresnel reflector. Parabolic Dish
Concentrator (PDCs) has the maximum concentration ratio (CR) among all the solar concentrators Mohammed et al. (2013). Solar energy from the sun is reflected on reaching the surface of the parabolic dish. The rays of light coming from the dish are focused at a point called the focus which gives it more concentrating power and hence increased temperature. With sufficiently higher temperature generated from parabolic dishes, Aidan (2014) stated that Pollution from fossil fuels and firewood can only be minimized if majority of the populace use cleaner and environmentally friendly sources of energy like solar and wind. Kleih (1991) set up a test facility for parabolic dish systems with power conversion unit in their focus, so as to experiment with a parabolic solar concentrator. The radiation losses can be small because of the small area of the absorber at the focus (Rai, 2005).

Nuwayhid et al. (2001) realized a simple solar tracking concentrator for university research applications. Murphree (2001) reported that a 
focus point of solar concentrator can be made from two troughs collectors by orienting their longitudinal axes in perpendicular directions and separating them by the difference of their focal lengths along the optical axis. Quederni et al., (2009), reported that parabolic solar concentrator has been used to measure solar flux and temperature distribution. Yaseen et al., (2015), stated that the concentrating type of heaters usually employs parabolic-concave mirror reflectors to condense the total solar energy incident on the collector surface which usually becomes very wide and the temperature achieved could therefore be very high. Akinpelu and Akoshile (2005) observed that drying in the solar chamber takes shorter time and occurs at relatively higher temperature. This shows that at high temperature there will be more evaporation.

\section{Theoretical Frame Work}

Parameters such as parabolic dish, calorimeters, thermometers, mirror and retort stands were used to compare solar reflection of light. These parameters are given below:

Collector area: it is the area of the collector that intercepts the solar radiation coming from the sun.

Receiver area: This is the total area of the receiver that absorbs solar radiation reflected from the parabolic dish.

Focal point: Is the point at which all the reflected rays from the parabolic dish are expected to converge.

Diameter of the dish: This is length of the dish from one end to another end

Parabolic dish of focal length $f$ with respect to the vertex of the solar dish has height $h$ and diameter $d$ which are related as shown in the equation below.

The equation of parabola in cylindrical coordinate is shown in equation 1 below:

$$
\mathrm{z}=\frac{r^{2}}{4 f} \quad 1
$$

The diameter of the opening parabolic surface is $d$, and the focal distance of the parabola is $f$. The surface of the parabola is given by the equation 2 below:

Schematic and construction of parabolic solar dish

The solar parabolic dish was constructed using DSTV dish satellite receiver. The diameters $(0.85 \mathrm{~m})$, and height $(0.65 \mathrm{~m})$ were measured to determine the focal length $(0.69 \mathrm{~m})$ of the reflecting rays.

$\mathrm{s}=\frac{8 \pi}{3} f^{2}\left\{\left[1+\left(\frac{d}{4 f}\right)^{2}\right]^{3 / 2}-1\right\} 2$

Where the cross-section of the opening parabola is given by the equation 3 below:

$a=\frac{\pi d^{2}}{4}$ 3

The focal distance of the solar concentrator to the calorimeter is shown in equation 4 below:

$f=\frac{d^{2}}{16 h}$ 4

Where $f$ is the focal length in meter, $d$ is the diameter in meter and $h$ is the height of the dish from the inner middle to the surface of the dish measure in meter. Mohammed (2013) and Folaranmi, (2009) reported that in Nigeria, many designs and constructions of solar parabolic dish collectors have been done. Different authors used other testing procedures which may be different from the international standard procedure developed Funk, (2000) and Mullick, (1991) for the evaluation of solar parabolic dish cookers.

Table 1: Parabolic Dish Reflector's Parameters

\begin{tabular}{|c|c|}
\hline Parameters & Measurements \\
\hline $\begin{array}{l}\text { Diameter of opening of the } \\
\text { parabolic dish }(d)\end{array}$ & $0.85 \mathrm{~m}$ \\
\hline Height of the parabolic dish (h) & $0.65 \mathrm{~m}$ \\
\hline Focal Point (f) & $0.69 \mathrm{~m}$ \\
\hline $\begin{array}{l}\text { Surface area of the parabolic } \\
\text { dish }(A)\end{array}$ & $0.57 \mathrm{~m}^{2}$ \\
\hline
\end{tabular}




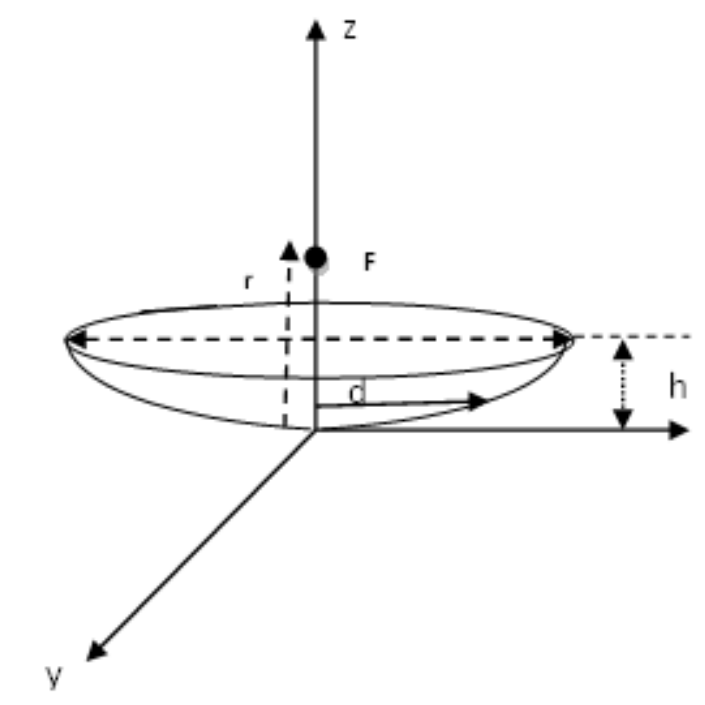

Figure 1: Schematic diagram of parabolic solar dish

\section{MATERIAL AND METHOD}

Three parabolic dishes overlaid with different materials were used during the experiment. The first dish was overlaid with glass that was cut in to smaller pieces and the second dish was overlaid with aluminum foil while the third dish was painted with silver colour. The dishes were placed under the sun to receive solar radiation coming from the sun. Three calorimeters (Model PH0455, Manufactured by EISCO in Rochester

\section{RESULT AND DISCUSSION}

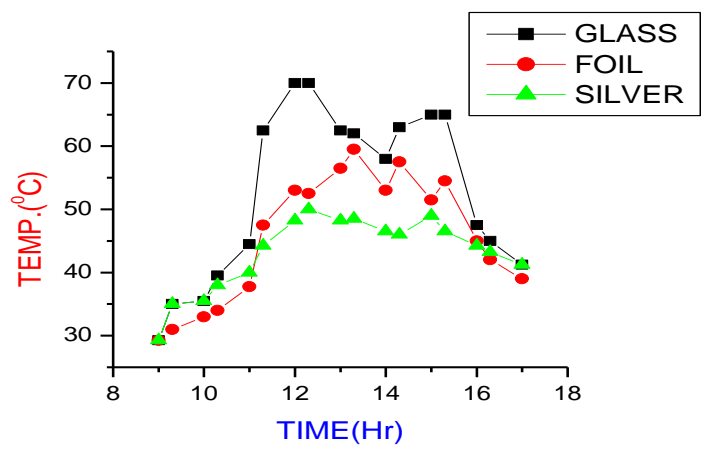

Figure 2: First day variation temperature and time using different materials
City of United States of America, USA) with thermometers inserted were filled with water and placed at the foci of the parabolic dishes. The calorimeters were held with a retort stands at the foci to receive solar reflection coming from the dishes. The dishes were rotated along the part of the sun ray to receive solar ray coming from the sun.

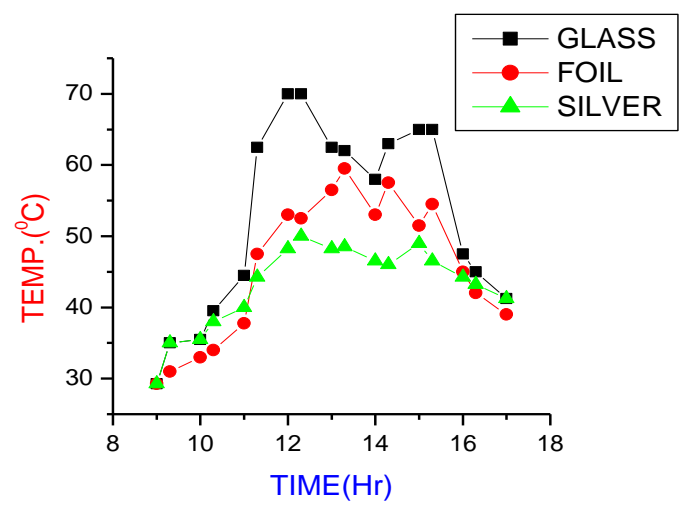

Figure 3: Second day variation temperature and time using different materials 


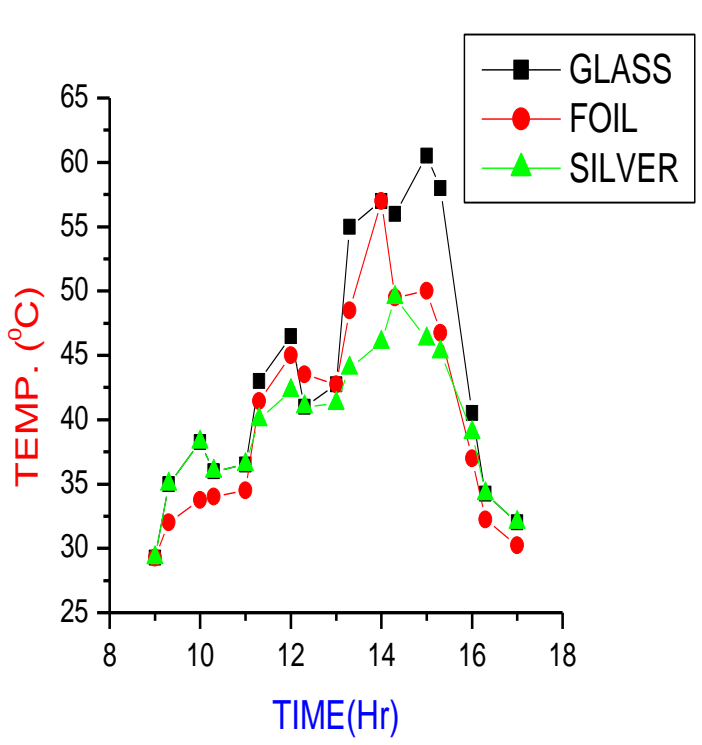

Figure 4: Third day variation temperature and time using different materials

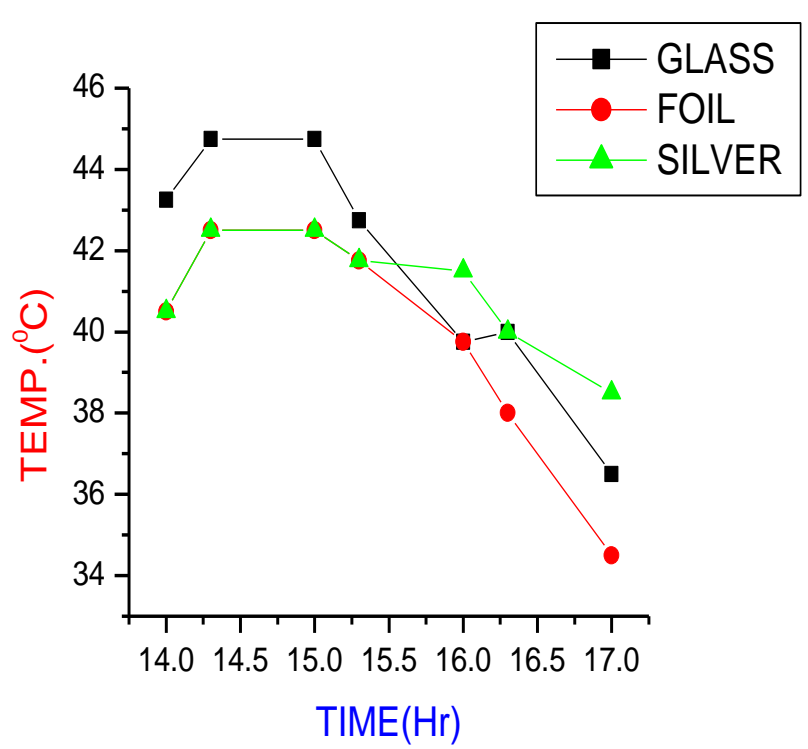

Figure 6: Fifth day variation temperature and time using different materials

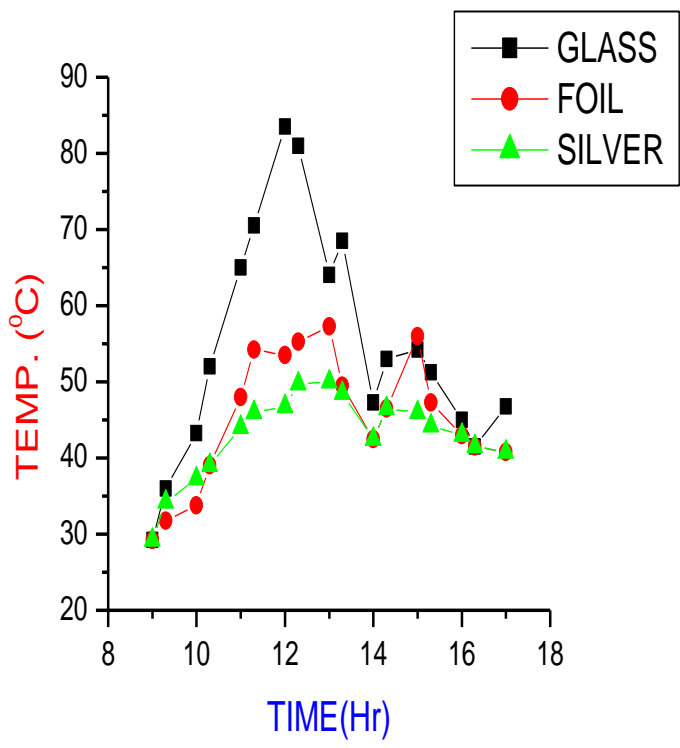

Figure 5: Forth day variation temperature and time using different materials

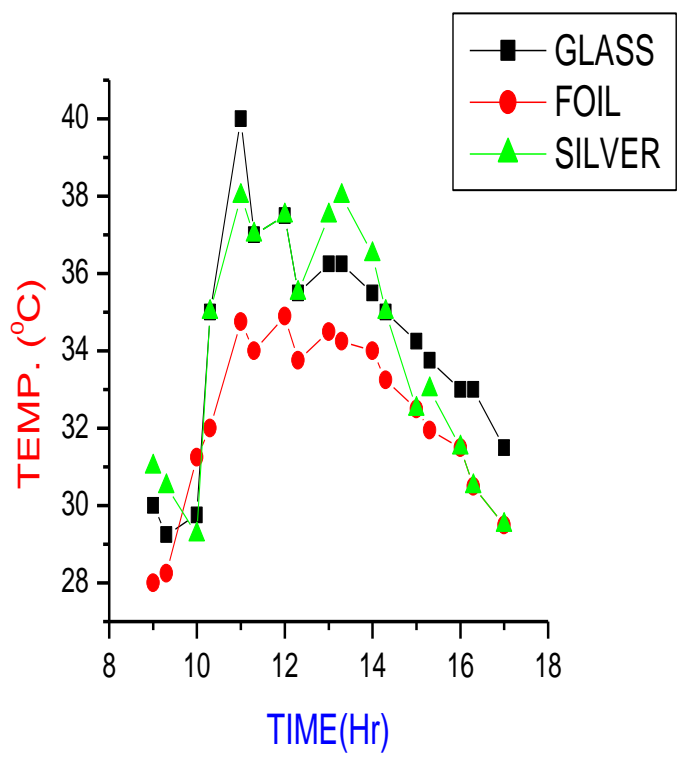

Figure 7: Sixth day variation temperature and time using different materials 


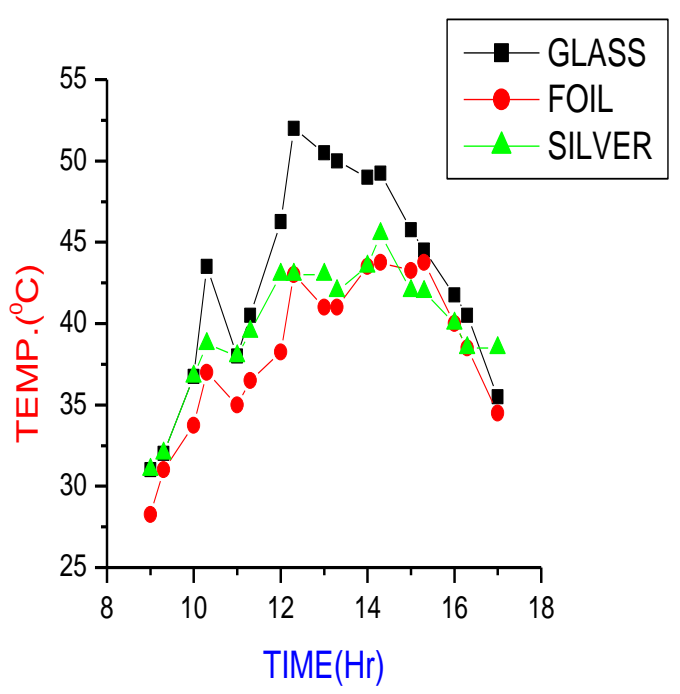

Figure 8: Seventh day variation temperature and time using different materials

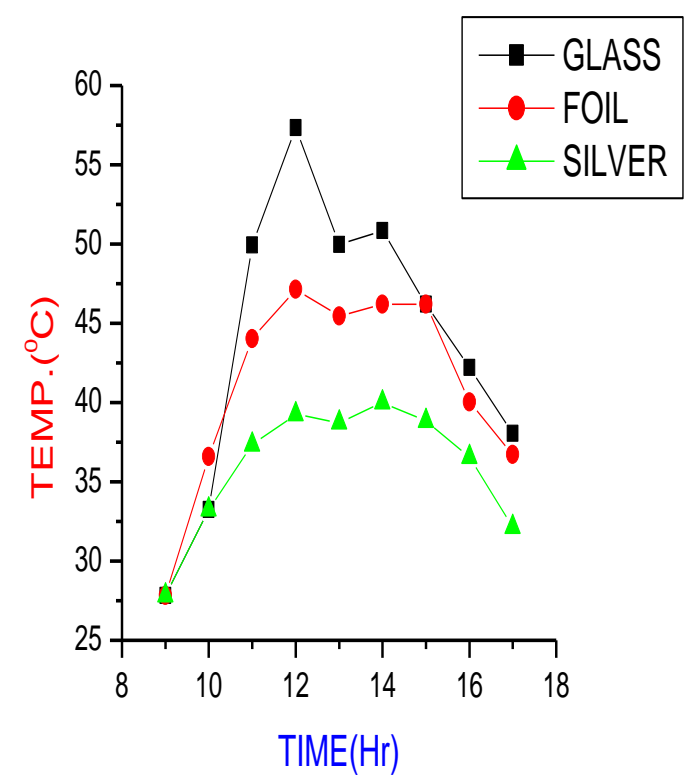

Figure 10: Second week variation temperature and time using different material

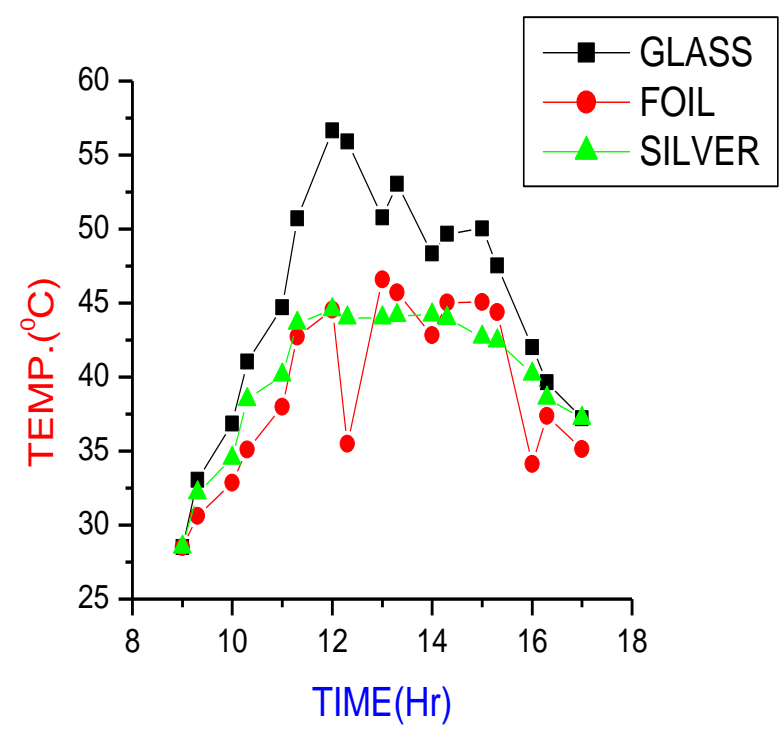

Figure 9: First week variation temperature and time using different material

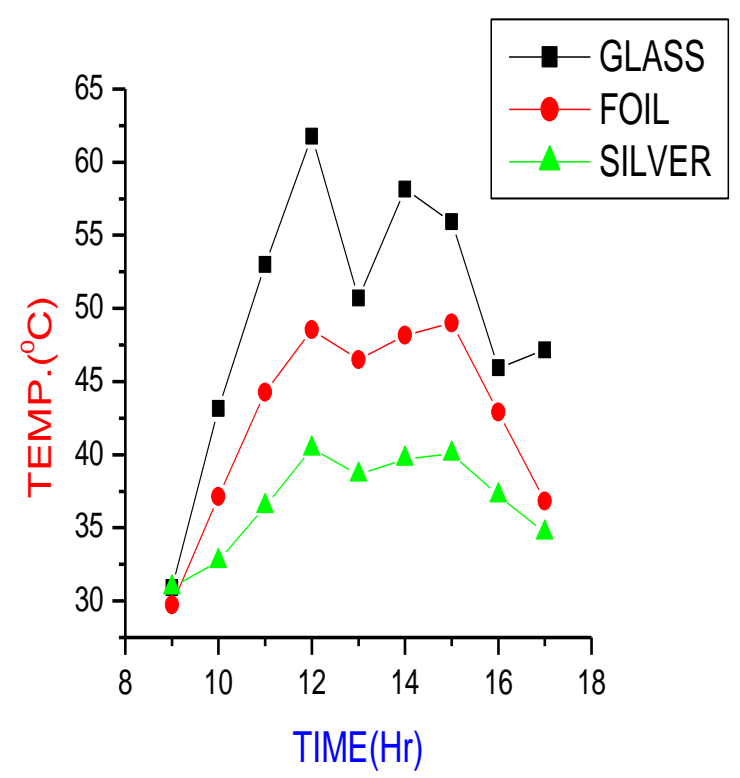

Figure 11: Third week variation temperature and time using different material 

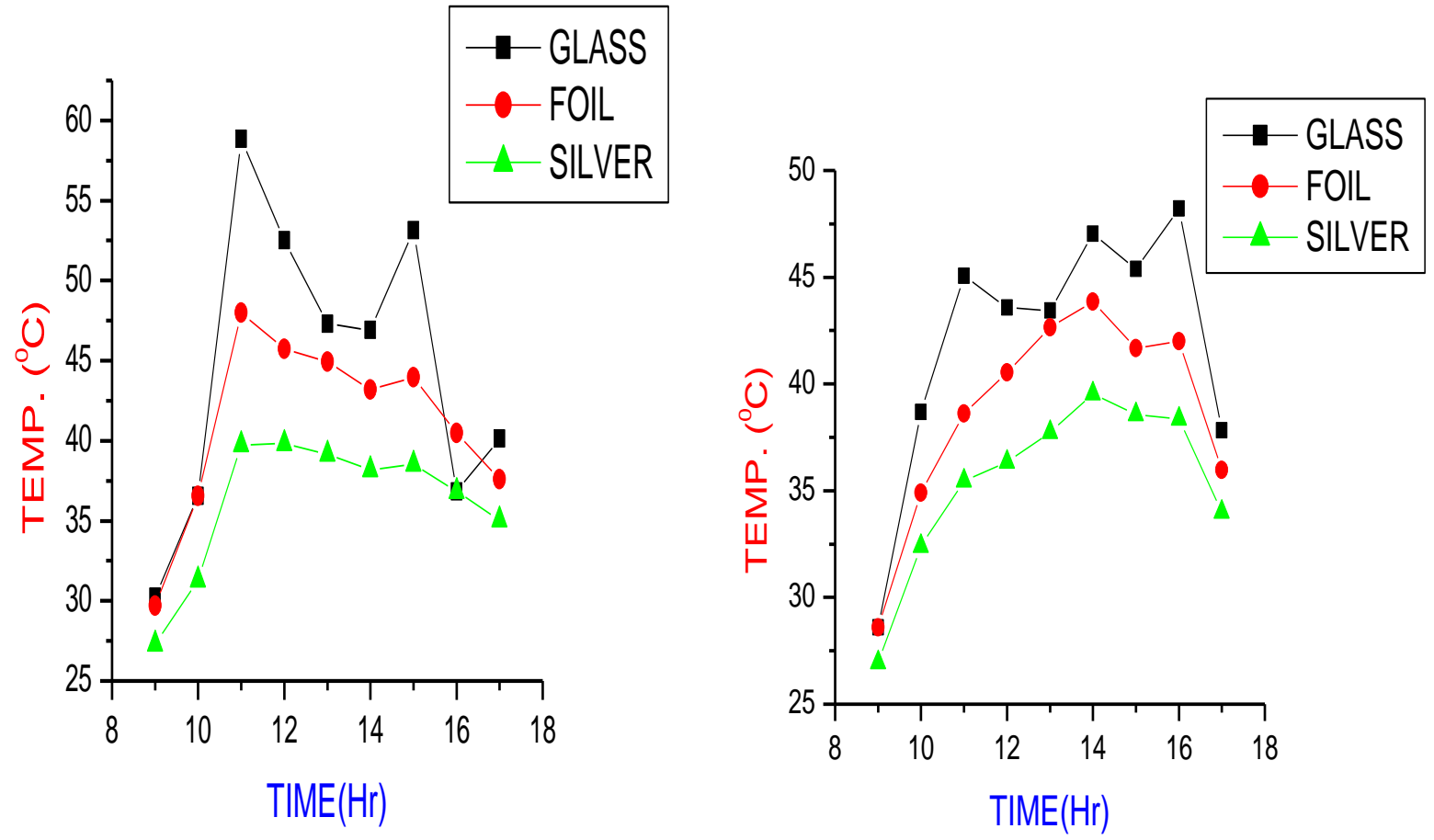

Figure 12: Forth week variation of temperature and time using different material

Figure 13: Fifth week variation temperature and time using different material

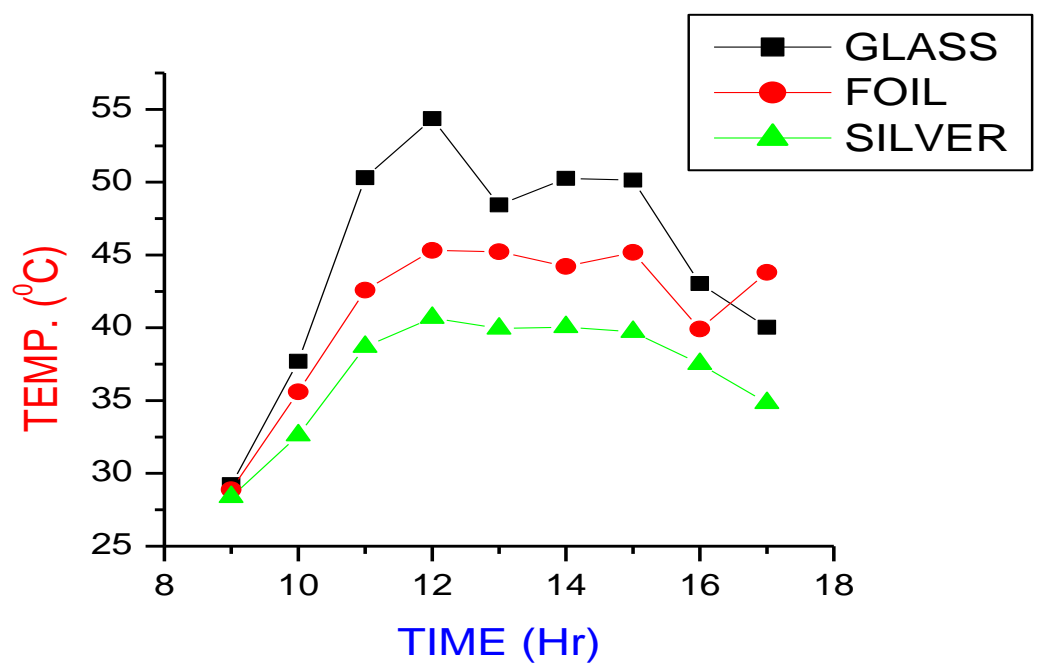

Fig 14: Weekly variation of temperature and time using different materials 


\section{Nigerian Journal of Basic and Applied Science (June, 2016), 24(1): 90-97}

\section{DISCUSSION}

From Figure 2 and 3 at around 9:00am, the temperature ranges from $25^{\circ} \mathrm{C}$ to $30^{\circ} \mathrm{C}$ for the three dishes. But gradually the temperature began to rise and got to its peak around 12:00 noon and the temperature rose along the same trend. Around 15:00 hour the temperature dropped a little which may be as a result of some atmospheric parameter such as cloud covering the sun rays at that particular time. But at 17:00 hour the temperature was higher than the morning period. From Figure 4: around 9:00 hour the temperature is almost equal to the first day temperature. But around 15:00 hour the temperature got to its peak (i.e $60^{\circ} \mathrm{C}$ ). But the temperature of all the dishes dropped drastically to around $40^{\circ} \mathrm{C}$ Figures 5, 7, 8,9,10 and 11 follow almost the same trend as compared with Figures $1,2,3,4$. This shows that the temperature at Iwo during the experimental study was almost equal for each day around the month of March and April. Meanwhile, Figure 6 shows a maximum temperature around 14:00 hour and which dropped drastically with foil having less temperature during the period of the experiment. Figure 14 shows the average temperature of all the weeks under consideration, which have it maximum temperature with the parabolic dish overlaid with glass material at around 12:00pm and followed by foil material and silver with lowest temperature. This may be attributed clear sky during the experiment, but there was a drop in temperature between the period of $12 \mathrm{pm}$ and $3 p m$ which may be attributed to cloudy sky during the experiment. Figure shows the rapid increment from $8 \mathrm{am}$ to $12 \mathrm{pm}$ which may be as a result of the clear sky during the experiment and rise in temperature from the sun. But it get to the maximum at around $3 \mathrm{pm}$. Table 1.0 is the dimension (diameter, height, focal point and surface area) of the dishes used during the research work.

\section{REFERENCES}

Aidan J., (2014). Performance Evaluation of a Parabolic Solar Dish Cooker in Yola,
The results show that the sun reaches it maximum radiation at noon which could give raise to increase in temperature of the water in the calorimeter. Latter there is a gradual decrement of the solar radiation reaching the earth surface. Yaseen et al., (2015), stated that the possibility of the direct increase in the solar radiation is proportionally with time which could reach the maximum at mid-noon followed by gradual decrease towards the sunset. But at some period during the experiment around noon there is a drop in solar radiation which could be attributed to cloud covering the sun. Parabolic dish with glass materials shows more of solar radiation as compared to dishes with foil and painted silver surface. The temperature variations of the dish proved that dish with glass material has the ability to cook faster because of its high concentration power. Aidan (2014) reported that it was possible to use solar parabolic dish collector as cooker to complement other conventional cooking devices in Yola especially between 11:00 am and 3:00 pm when the solar radiation is considered higher. But at Iwo such device can be used around 12 noon to about $3 \mathrm{pm}$ when there is increment in the solar radiation reaching the town. Yaseen et al., (2015) reported that the parabolic solar concentration had succeeded in operating with temperatures higher than any other different types of the solar radiation and in desalination of water for potable water and domestic usage pending on both accurate adjustment and increased at preheating method.

\section{CONCLUSION}

The results shows that the parabolic dish overlaid with glass material has more temperature performance has compared with the other dishes.

Nigeria. IOSR Journal of Applied Physics, 6(5): 46-50.

Akinpelu, J. A. and Akoshile, C. O., (2005). Solar Chimney Dryer. Nigerian Journal of Solar Energy, 15: 133-142. 
Folaranmi, J., (2009). Design, construction and testing of a parabolic solar steam generator, Leonardo Electronic Journal of Practices and Technologies, 14: 115133.

Funk, A. P., (2000). Evaluating the international standard procedure for testing solar cookers and reporting performance, Solar Energy, 68(1): 1-7.

Kleih, J. (1991). Dish-Stirling test facility, Solar Energy Materials, 24(1-4): 231 - 237.

Manav S., Jaykumar V., Nitesh B., Niranjan S. and Vijay.C. G., (2015). Design, fabrication and analysis of helical coil receiver with varying pitch for solar parabolic dish concentrator. International Journal on Theoretical and Applied Research in Mechanical Engineering, 4(2): 49-54.

Muhammad-Sukki, F. Ramirez-Iniguez, Scott G McMeekin, Brian G. and Stewart., (2012). Barry Clive: "Solar concentrators"; International Journal of Applied Sciences, 1(1): 1-15.

Mohammed, I. L., (2013). Design and development of a parabolic solar thermal cooker, International Journal of Engineering Research and Applications, 3(4): 1179-1186.

Mullick, S. C., Kandpal T. C. and Kumar, S. (1991). Thermal test procedure for a parabolic concentrator solar cooker, Solar Energy, 46, 139-144.

Murphree, C.Q. (2001). A Point Focusing Double Parabolic Through Concentrator, Solar Energy, 70(2): 85 - 94.

Nuwayhid, R.Y. Mrad, F. and Abu-Said, V. (2001). The realization of a Simple Solar Tracking Concentrator for University Research Applications, Renewable Energy, 24(2): 207 - 222.

Ouederni, El. A.R. Ben Salah, M., Askri, V. Ben Nasrallah M. and Aloui, F., (2009). Experimental study of a parabolic solar concentrator. Revue des Energies Renouvelables 12(3): 395 - 404.

Rai G. D. 2005. Solar Energy Utilization. Delhi, India: Khanna Publishers.
Yaseen H.M., Rafea A. M and Ayoub A. B.(2015). Modulating a Solar Parabolic Dish to Produce Boiled water. Journal of Environmental Science and Engineering. A,4: 225-232. 